\title{
A rare cause of periorbital swelling
}

\author{
Laura Leach, Chloe Swords, Nazir Bhat
}

Department of

Otorhinolaryngology, North West Anglia NHS Foundation Trust, Peterborough, UK

\section{Correspondence to Laura Leach,}

laura.leach1@nhs.net

Accepted 18 February 2018

\section{DESCRIPTION}

A 70-year-old man was admitted under the medical and ophthalmology team with a 1-day history of sudden-onset, right-sided, periorbital swelling. $\mathrm{He}$ denied any broken skin or local trauma. He had no relevant medical history and was not immunocompromised. On initial examination, the periorbital area was swollen, erythematous and indurated, with desquamation of the lower lid. There were no orbital signs. The patient was mildly tachycardic but afebrile. An urgent CT head demonstrated orbital cellulitis predominantly involving the preseptal space with some intraorbital extension. A degree of maxillary and ethmoid sinus opacification was also noted. A diagnosis of orbital cellulitis secondary to acute sinusitis was made, and the patient was started on intravenous Tazocin, as per local microbiology guidance.

There was initial improvement in clinical symptoms and laboratory markers; however, 48 hours after starting antibiotics, the infraorbital area deteriorated and appeared necrotic and increasingly swollen (figure 1). ENT (ear, nose and throat) input was requested to assess the possibility of acute sinusitis necessitating sinus drainage. ENT excluded acute sinusitis as the cause of orbital cellulitis following clinical and nasendoscopic examination. A repeat CT showed new preseptal gas formation in keeping with necrotising fasciitis (NF) (figure 2). The patient was taken urgently to the theatre for
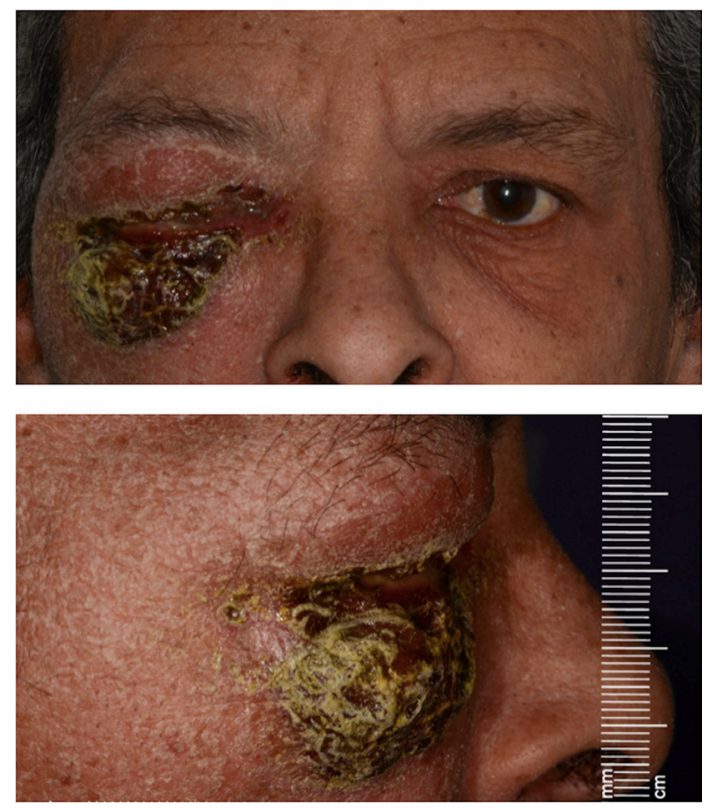

Figure 1 Anterior and lateral views demonstrating right-sided periorbital swelling with infraorbital necrosis with the typical scarlatiniform colouration associated with necrotising fasciitis.

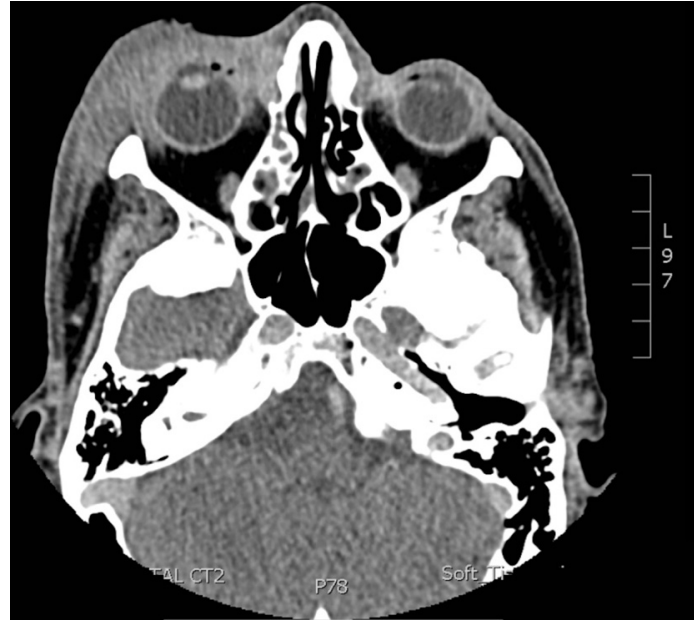

Figure 2 Axial plane CT demonstrating extensive right-sided preseptal cellulitis, mild extension into the retroconal space laterally and air locules anterior to the globe, in keeping with necrotising fasciitis.

debridement. Necrotic skin, orbicularis oculi and adipose tissue were debrided, with preservation of the tarsal margin. Group A (beta-haemolytic) streptococcus was isolated from the wound cultures. The patient had a good postoperative recovery and the wound granulated well. He was discharged with metronidazole and once-daily intravenous ceftriaxone, with maxillofacial and oculoplastic follow-up.

Orbital cellulitis is commonly caused secondary to acute sinusitis, following the spread of infection through the lamina papyracea. However, radiological evidence of sinus opacification in patients presenting with orbital cellulitis is not diagnostic of orbital cellulitis secondary to acute sinusitis. In fact, CT findings of sinus opacification are a common, non-specific finding. CT, while valuable, is not a substitute for ENT assessment and nasendoscopic examination. It is important to involve specialists early who can assist in diagnosis. This case demonstrates that rare differentials must always be considered, especially when symptoms of acute sinusitis are not present.

NF is a serious, life-threatening infection of the subcutaneous tissue and underlying fascia. ${ }^{1} \mathrm{NF}$ of the periorbital region is extremely rare, with a UK incidence of 0.24 per million per annum. ${ }^{2}$ Periorbital NF often develops following trauma; however, interestingly this patient developed unprovoked NF. ${ }^{2}$ Patients with NF are typically systemically unwell, often with septic shock, and are classically immunocompromised or diabetic. ${ }^{4}$ However, as with this case, patients with periorbital NF are more likely to remain systemically 
well with the infection and are often healthy, non-immunocompromised individuals; Amrith et $\mathrm{al}^{5}$ found that $52.1 \%$ of patients had no prior pre-existing illness. This may further lower the clinical suspicion of NF and result in misdiagnosis. ${ }^{6}$ It is therefore important to always consider NF as a differential in cases of periorbital cellulitis and keep a high index of suspicion. Periorbital NF is associated with significant

\section{Learning points}

- Periorbital necrotising fasciitis often occurs in non-immunocompromised individuals, who can remain systemically well and can occur without any history of trauma.

- Misdiagnosis is common in necrotising fasciitis. ${ }^{6}$ Clinicians should have a high index of suspicion when assessing patients with cellulitis, especially those who deteriorate despite antibiotic therapy.

- CT findings of sinus opacification are a common finding and are not diagnostic of acute sinusitis. $\mathrm{CT}$, while valuable, is not a substitute for ENT (ear, nose and throat) assessment and nasendoscopic examination.

- This case highlights the importance of a multidisciplinary approach to the management of cellulitis. Local hospital cellulitis guidelines should include early surgical consult to assist in diagnosis, with either ENT, general surgery, orthopaedics or plastic surgery depending on the anatomical location. Prompt diagnosis and early surgical debridement can prevent mortality and reduce morbidity. morbidity, including loss of vision (14\%), soft-tissue defects affecting cosmesis and function, and a 3.4\%-10\% risk of mortality. ${ }^{23}$ Repeat assessment and examination of the patient is important, as prompt diagnosis and early surgical debridement are crucial in reducing this risk. ${ }^{78}$

Contributors LL: drafting of manuscript. CS and NB: reviewing and revising of manuscript.

Funding The authors have not declared a specific grant for this research from any funding agency in the public, commercial or not-for-profit sectors.

Competing interests None declared.

Patient consent Obtained.

Provenance and peer review Not commissioned; externally peer reviewed.

(c) BMJ Publishing Group Ltd (unless otherwise stated in the text of the article) 2018. All rights reserved. No commercial use is permitted unless otherwise expressly granted.

\section{REFERENCES}

1 Sultan HY, Boyle AA, Sheppard N. Necrotising fasciitis. BMJ 2012;345:e4274.

2 Flavahan PW, Cauchi P, Gregory ME, et al. Incidence of periorbital necrotising fasciitis in the UK population: a BOSU study. Br J Ophthalmol 2014:98:1177-80.

3 Rajak SN, Figueira EC, Haridas AS, et al. Periocular necrotising fasciitis: a multicentre case series. Br J Ophthalmol 2016;100:1517-20.

4 Lancerotto L, Tocco I, Salmaso R, et al. Necrotizing fasciitis: classification, diagnosis, and management. J Trauma Acute Care Surg 2012;72:560-6.

5 Amrith S, Hosdurga Pai V, Ling WW. Periorbital necrotizing fasciitis -- a review. Acta Ophthalmol 2013;91:596-603.

6 Goh T, Goh LG, Ang CH, et al. Early diagnosis of necrotizing fasciitis. Br J Surg 2014;101:e119-e125.

7 Kiat HJ, En Natalie YH, Fatimah L. Necrotizing Fasciitis: How Reliable are the Cutaneous Signs? J Emerg Trauma Shock 2017;10:205-10.

8 Stevens DL, Bryant AE. Necrotizing Soft-Tissue Infections. N Eng/ J Med 2017;377:2253-65

Copyright 2018 BMJ Publishing Group. All rights reserved. For permission to reuse any of this content visit

http://group.bmj.com/group/rights-licensing/permissions.

BMJ Case Report Fellows may re-use this article for personal use and teaching without any further permission.

Become a Fellow of BMJ Case Reports today and you can:

- Submit as many cases as you like

- Enjoy fast sympathetic peer review and rapid publication of accepted articles

- Access all the published articles

- Re-use any of the published material for personal use and teaching without further permission

For information on Institutional Fellowships contact consortiasales@bmjgroup.com

Visit casereports.bmj.com for more articles like this and to become a Fellow 